\title{
Informe de la Conferencia Temática UGI - IGU “Las Geografías de la Paz", Bolivia 2017
}

\author{
Report of the UGI - IGU Thematic Conference "The Geographies of \\ Peace", Bolivia 2017
}

\section{Relatório da Conferência Temática UGI - IGU "As Geografias da Paz", Bolívia 2017}

\author{
Juan Manuel Delgado Estrada \\ Universidad Nacional Mayor de San Marcos/ Universidad de Barcelona/CLACSO/UGI \\ https://orcid.org/0000-0002-2770-082X \\ juan.delgado10@unmsm.edu.pe
}

\begin{abstract}
RESUMEN
La geografía generalmente ha sido acusada de ser útil sobre todo para hacer la guerra. Por el contrario, puede ofrecer una amplia gama de contribuciones a la construcción de la paz y la solución de conflictos socioterritoriales de diversas escalas nacionales o locales. Las "Geografías Por la Paz" del 2017 fue una conferencia temática de la Unión Geográfica Internacional, que tuvo como objetivo si es posible desde una entrada transdiciplinaria su estudio, en este sentido, desde el punto de vista histórico y el papel de las actividades que construyen socialmente el espacio de la "Paz" como la educación, cultura, política, economía o el turismo, pues para el análisis sociopolítico de la guerra y la paz es necesario realizar ese ejercicio de la medición del poder y su impacto en el territorio multiescalar. Realizar esta reseña o comentario del evento del 2017, lo consideramos muy relevante y actual por la coyuntura que se vive en plena pandemia de la Covid - 19 a escala global y local, que es una disputa entre el estado y el virus Sars Cov-2 del territorio a través del terror (territor) o territorialidad/desterritorialidad que nos hace recordar esa liminalidad entre la Paz y la Guerra. Así mismo, nos visibiliza la importancia de los eventos académicos de la UGI y su influencia en el pensamiento geográfico de los países receptores del evento, los antecedentes y las coyunturas que se dan en el antes, durante o después de eventos de estas características, posibles legados y criticas al respecto de esta actividad académica como fue la Conferencia Temática UGI Bolivia 2017.
\end{abstract}

\begin{abstract}
Geography has generally been accused of being useful especially in waging war. Rather, it can offer a wide range of contributions to peacebuilding and socio-territorial conflict resolution on various national or local scales. The "Geographies for Peace" of 2017 was a thematic conference of the International Geographical Union, whose objective was, if possible, from a transdisciplinary entry, its study, in this sense, from the historical point of view and the role of the activities that socially construct the space of "Peace" such as education, culture, politics, economy or tourism, because for the sociopolitical analysis of war and peace it is necessary to carry out this exercise of measuring power and its impact
\end{abstract}

\section{Citar como:}

Delgado, J. (2021). Informe de la Conferencia Temática UGI - IGU “Las Geografías de la Paz”, Bolivia 2017. Espiral, revista de geografías y ciencias sociales, 3(5), 147-158. https://dx.doi.org/10.15381/espiral.v3i5.21277 
on the multiscale territory. To make this review or comment of the 2017 event, we consider it very relevant and current due to the situation in the midst of the Covid-19 pandemic on a global and local scale, which is a dispute between the state and the Sars Cov-2 virus of the territory through terror (territory) or territoriality / deterritoriality that reminds us of that liminality between Peace and War. Likewise, it makes us visible the importance of the academic events of the UGI and their influence on the geographical thinking of the countries receiving the event, the antecedents and the conjunctures that occur before, during or after events of these characteristics, possible Legacies and criticisms regarding this academic activity, such as the UGI Bolivia Thematic Conference 2017.

\section{RESUMO}

Ageografia tem sido geralmente acusada de ser útil, especialmente na guerra. Em vez disso, pode oferecer uma ampla gama de contribuições para a construção da paz e resolução de conflitos socioterritoriais em várias escalas nacionais ou locais. O "Geographies for Peace" de 2017 foi uma conferência temática da União Geográfica Internacional, cujo objetivo era, se possível, a partir de um verbete transdisciplinar, o seu estudo, neste sentido, do ponto de vista histórico e o papel das atividades que construir socialmente o espaço da "Paz" como educação, cultura, política, economia ou turismo, pois para a análise sociopolítica da guerra e da paz é necessário realizar este exercício de medição do poder e seu impacto no território multiescala. Para fazer esta revisão ou comentário do evento de 2017, consideramos muito relevante e atual devido à situação em meio à pandemia Covid-19 em escala global e local, que é uma disputa entre o estado e o Sars Cov- 2 vírus do território através do terror (território) ou territorialidade / desterritorialidade que nos lembra aquela liminaridade entre Paz e Guerra. Da mesma forma, nos torna visíveis a importância dos eventos acadêmicos da UGI e sua influência no pensamento geográfico dos países receptores do evento, os antecedentes e as conjunturas que ocorrem antes, durante ou depois de eventos dessas características, possíveis Legados e críticas em relação a esta atividade acadêmica, como a Conferência Temática UGI Bolívia 2017.

PALABRAS CLAVE: Geografías de La Paz; Latinoamerica; Guerra; Conferencia Temática; Bolivia.

KEYWORDS: Geographies For Peace; Latin America; War; Thematic Conference; Bolivia.

PALAVRAS CHAVES: Geografias de La Paz; América latina; Guerra; Conferência Temática; Bolívia.

\section{Introducción}

Históricamente la Union Geográfica Internacional - UGI ${ }^{1}$ ha sido catalogada de colonial y vista muy lejana a nuestra realidad de Latinoamerica y el Caribe, probablemente debido a la realización de su primer Congreso Geográfico Internacional ${ }^{2}$ en Amberes durante 1871 en la Bélgica Imperial y dada la coyuntura controversial del Rey Leopoldo II que en el año 1876 convoco la Conferencia Geográfica de Bruselas ${ }^{3}$ para que después sea gobernante del Congo Belga o "Estado Libre del Congo" entre 1885 - 1908, tenía a la geografía como un instrumento colonial por la división del África a favor de los países europeos a través de sus sociedades comerciales geográficas imperiales que bajo el pretexto filantrópico y de protección a ese continente y a sus habitantes fue todo lo contrario ${ }^{4}$, eso se quedó en la memoria colectiva de los geógrafos y geógrafas de la primera parte del siglo $X X^{5}$.

Después del primer y último Congreso Internacional de Geografia, realizado en Rio de Janeiro en 1956, impulsada por los geógrafos franceses que radicaban y enseñaban en la antigua Universidad de Brasil, (hoy Universidad Federal de Rio de Janeiro),

1 Los paises que participaron en su creación fueron: Italia, Japon, Portugal, Bélgica, Francia, Gran Bretaña y España fueron en 1922 en Bruselas. El 2022 se celebrará el Congreso Internacional Geográfico Centenario de la creación de la UGI en Paris - Francia" El tiempo de los geógrafos". https://www.ugiparis2022.org/.

2 El $2^{\text {do }}$ Congreso Geográfico Internacional se realizó en 1875 en Paris, Francia, con la participación de exploradores, académicos y sociedades geográficas de los imperios europeos.

3 En 1876 Leopoldo II convocó con éxito la Conferencia Geográfica de Bruselas donde reúne además de académicos a políticos y empresarios habidos de expandir sus rutas comerciales y explotar los recursos naturales del África.

4 "El corazón de las tinieblas" fue escrito en 1899 por el inglés de origen polaco Joseph Conrad, quien nos narra el colonialismo belga en el río Congo, donde el terror se implanto en su población nativa para la explotación de sus recursos naturales como marfil, caucho y diamantes.

5 Existe una crítica valida a la "colonialidad del poder" desde la geopolítica del conocimiento del rol eurocéntrico de la UGI, en cuestiones quizás secundarias para unos pero principales para los y las geógrafas como el uso de los idiomas inglés y francés como oficiales, aunque ahora el español también es oficial. La centralidad en los países del norte de los eventos mundiales y regionales también repercuten en esa percepción hegemónica y lejana la respecto. 
creada en el año 1950. Luego de ese importante evento, no se ha vuelto a organizar uno con esas características en Latinoamerica y el Caribe.

Después de ese Congreso Internacional de Geografia de Rio de Janeiro en 1956, son exactamente 65 años sin un evento mundial de Geografia en América Latina, Caribe o Norteamérica. Mención aparte fueron las Conferencias Regionales de la UGI realizadas en Ciudad de México en 1966, luego en 1982 en Rio de Janeiro, Brasil y 1995 en La Habana, Cuba. En el 2007 en la Universidad de Buenos Aires se realizó la Conferencia de la Comisión La Aproximación Cultural en Geografía de la UGI', luego en Chile en el año 2011 se realizó la última Conferencia Regional UGI en nuestra región, que tuvo diversos problemas y contradicciones propias de la sociedad chilena y latinoamericana, sobresaliendo que su desarrollo haya sido en el local de la Escuela Militar de $\mathrm{Chile}^{7}$, otra crítica fueron los altos precios para participar porque estaban por encima de la media del costo de un evento académico en los países de América Latina y el Caribe, probablemente por el alto costo de vida en el país anfitrión y las crisis económicas en varios países vecinos lo hacían percibir así, debido a ello se tuvo escasa participación de los/las colegas latinoamericanos y quizás lo más impactante fue el boicot internacional y nacional porque la sede del evento fue cuestionada por ser un centro de tortura ${ }^{8}$, con la salvedad que ya la UGI internamente desde el 2010 tenía problemas con su Conferencia Regional de Tel Aviv, Israel ya que muchos geógrafos y geógrafas especialmente europeos llamaron a no participar en el evento por los bombardeos a población civil en los territorios ocupados de Palestina entre el 2008 - 2010, pero lo que rebalsó todo fue el ataque a la "flotilla (humanitaria) de Gaza" de parte del ejército Israelí. Después del 2011 se acordó en el Consejo Ejecutivo de la UGI que ninguna sede (ciudad) o local de los eventos de la UGI - IGU debería de tener controversias legales, políticas, éticas o con los derechos humanos como sucedió con sus dos eventos regionales del 2010 y 2011 respectivamente.

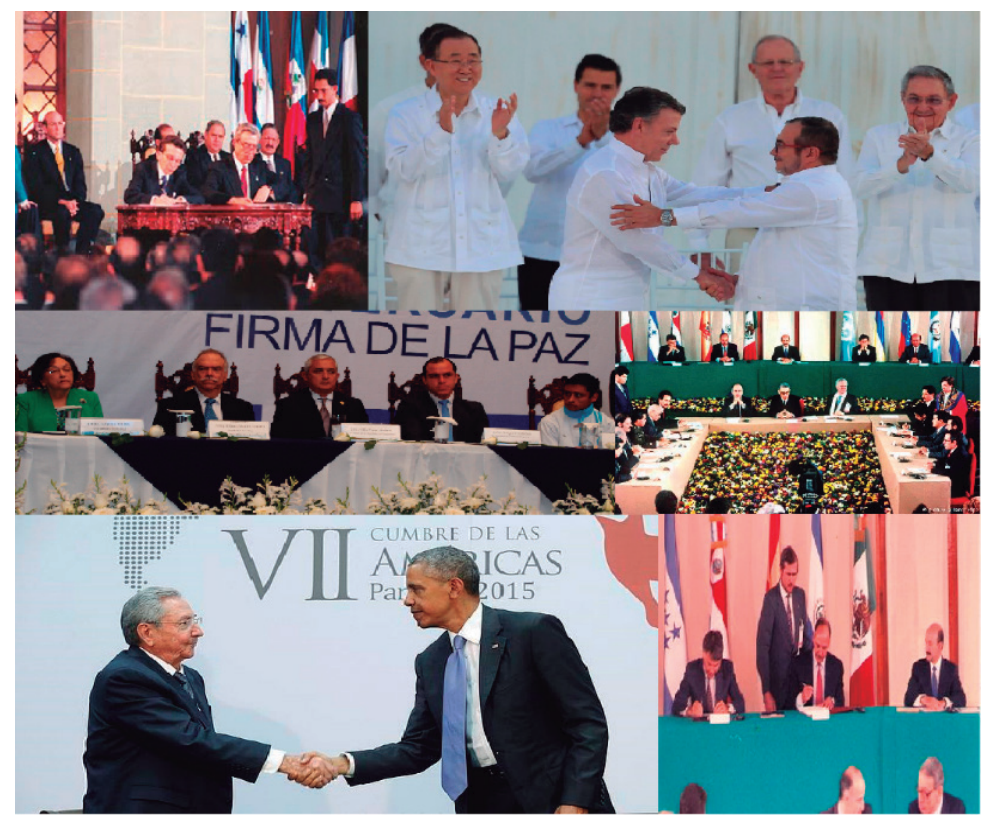

Figura 1. Collage de imágenes de la Paz en Latinoamerica y el Caribe Fuente: Informe de la Conferencia Temática Geografías de la Paz 2017 UGI.

Elaboración Propia luego de seleccionar imágenes de los procesos de paz en nuestro continente (Colombia, Cuba, Guatemala y El Salvador).

6 Creada en 1996 durante la Conferencia Internacional Geográfica en La Haya - Paises Bajos. La conferencia Internacional del 2007 tuvo el título de "Aspectos culturales en las Geografías Económicas, Sociales y Políticas" y tiene un libro con las memorias del evento editado por la Universidad de Buenos Aires: http://publicaciones.filo.uba.ar/sites/publicaciones. filo.uba.ar/files/Geograf\%C3\%ADas\%20culturales_interactivo.pdf

7 El cual fue una instalación militar utilizada como centro de detención política y tortura para la población civil en la dictadura militar de Augusto Pinochet (Herceg, 2016).

8 https://www.petitions.net/para_exigir_a_ugi_que_cambie_sede_de_la_conferencia_regional_2011 
Existe una relación en Latinoamérica y el Caribe de una geografía militar o militarizada por la tradición militar en los campos de la cartografía e ingeniería de la mayoría de los países de nuestro continente de crear sus institutos cartográficos o geográficos y muy pocos de origen civil, aunque muchos hayan modificado su nombre de "Militar" a "Nacional", pues en la práctica son los militares quienes continúan dirigiéndola a la fecha.

Otra forma de agresión fueron los cierres intempestivos de los departamentos y los institutos en periodos de dictaduras militares como sucedió en Chile (Quiroz y Narváez, 2014), luego en Bolivia en la dictadura del General Banzer9, así como en el Perú en 1995 con la dictadura de Alberto Fujimori ( ver Resolución Rectoral N ${ }^{\text {ro }}$ 5050 - Comisión Reorganizadora - 95), todas estas acciones que representan a los poderes nacionales en la academia de la geografía en estos países nos da señales del enfoque y el objeto de estudio de la geografía latinoamericana y caribeña desde las ramas de la "Geografia Militar" como son la ingeniería (geodesia y topografía) y la cartografía hasta el día de hoy, por esto probablemente y otros sucesos más es lo que han alejado muchos geógrafos y geógrafas de participar en las actividades del Instituto Panamericano de Geografia e Historia - IPGH, institución que depende de la Organización de Estados Americanos - OEA, esta "supuesta" militarización de la geografía en la institucionalidad académica podría ser que también afecto a la UGI - IGU en esas "controversias", porque los pocos comités nacionales representantes activos en Latinoamerica y el Caribe en el 2006 eran Chile y Argentina con los Institutos Geográficos Nacionales o Militares respectivos, mientras que México lo era a través de la Sociedad Mexicana de Geografía y Estadística y Cuba a través del Instituto de Geografia Tropical, además de dos miembros observadores como Perú y Brasil (Palacio- Prieto, 2006).

\section{Geografías de La Paz}

El objetivo principal de la conferencia temática "Geografías de La Paz", estaba centrado en realizar incidencias para tener un acercamiento de la Unión Geográfica Internacional - UGI a los geógrafos y geógrafas de Latinoamérica y el Caribe, debido a que existen interés de universidades, institutos, centros de investigación, asociaciones, colegios profesionales o sociedades geográficas en participar activamente y ser parte de las comisiones de trabajo esto según los informes anuales de la Comisión de Estudios Latinoamericanos desde el 2012, desde el interés de participar en los eventos organizados o auspiciados de la UGI, además de ser sedes de próximos eventos o de tener una membresía como comité nacional.

Durante los últimos años atrás la UGI está en un proceso lento de consolidación de su presencia en América Latina y el Caribe, consideran que es necesario insistir en organizar un "Congreso Mundial de Geografías o Conferencia Regional", lamentablemente se tienen que esperar hasta los años 2026 o 2028 pues son las fechas libres más próximas para alguna postulación de ser sede. También se tiene conocimiento que está en proceso por implementar un evento propio de la Comisión de Estudios Latinoamericanos y Caribeños de la UGI 2020 - 2024, según los propulsores desde la UGI de esta iniciativa se desea coordinar con los organizadores del EGAL - Encuentro de Geógrafos de America Latina teniendo como un criterio es que se realice en un año par y no coincida con el evento EGAL, además que se debe considerar que se vea y perciba como un complemento a otros eventos geográficos latinoamericanos y caribeños para impulsar el quehacer geográfico de nuestra región.

9 ..."En 1971, como consecuencia de la nueva situación política del país, se crea el "Consejo Nacional de Educación Superior" (CENES), el mismo que suprime la Facultad de Ciencias Geológicas y crea en su lugar el "Departamento de Geociencias" dependiente de la Facultad de Ciencias Puras y Naturales, situación que mantiene hasta 1984"...(Fuente: https://fcg. umsa.bo/ingenieria-geografica ). 


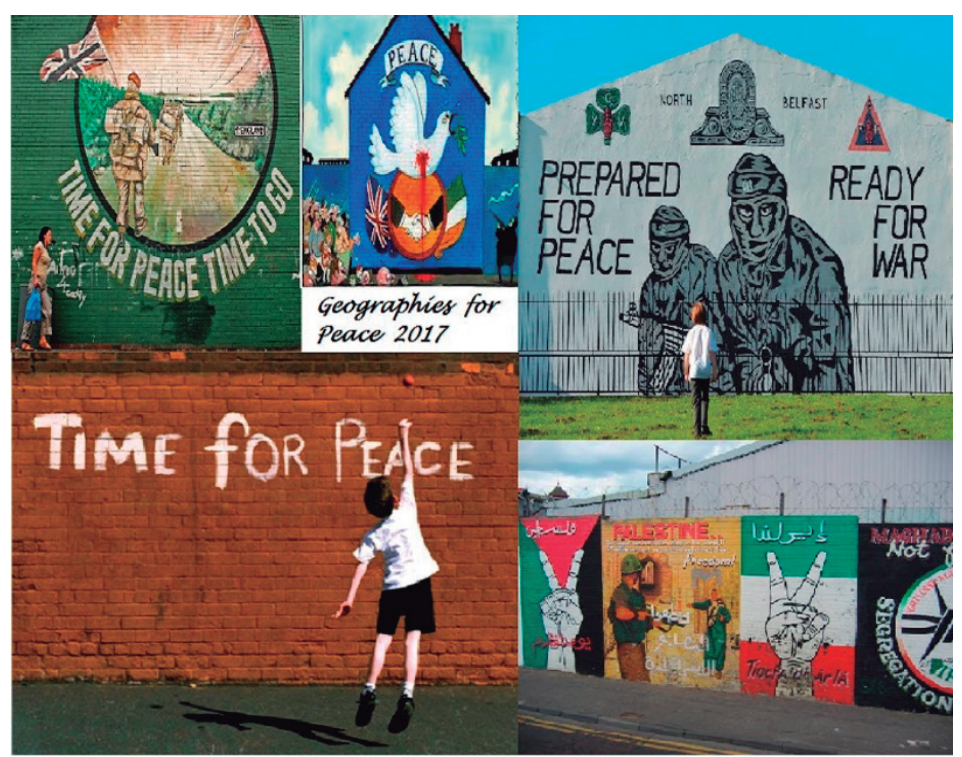

Figura 2. Imágenes de la Paz en las calles de Irlanda

Fuente: Informe de la Conferencia Temática Geografías de la Paz 2017 UGI.

Elaboración propia de diversas fotografías sobre el conflicto armado en Irlanda.

\section{La Conferencia Temática 2017}

Los antecedentes de la Conferencia Temática se inician en el año 2015 cuando el directivo Ing. Javier Nuñez Villalba de la UGI - Bolivia y de la Comision de Estudios Latinoamericanos se reunió en la Habana, Cuba con la profesora Elena Dell'Agnese quien en ese entonces era parte del Comité Ejecutivo Mundial de la UGI, en el marco del XV EGAL 2015, donde se inició la idea de organizar un pre - evento al próximo XVI EGAL La Paz 2017. Siendo luego refrendado esta idea en La Paz - Bolivia 2016, cuando se realizó el convenio UGI - Perú y la UMSA (Universidad Mayor de San Andrés).

En el mes de febrero del 2017, se tuvo una reunión virtual entre miembros del Comité Directivo de la Comisión de Estudios Latinoamericanos ${ }^{10}$ dirigida desde La Paz, Bolivia para planificar y ajustar acciones previas a la Conferencia Temática “Geografías Por la Paz" de abril del 2017, en dicha reunión, participaron los colegas José Becerra de Venezuela, Adrián Flores de México, Javier Núñez de Bolivia, quienes participaron por su nivel de directivos de la Comisión de Estudios Latinoamericanos de la UGI, se coordinó las actividades del 2017 especialmente la organización de la Conferencia Temática en los próximos meses en Bolivia.

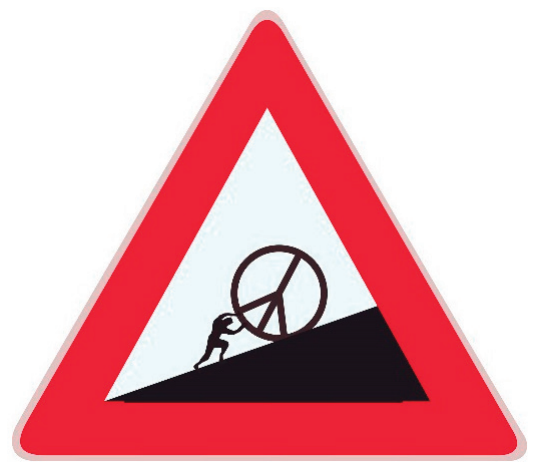

Figura 3. Logo de la Conferencia Temática "Geografías Por la Paz"

Fuente: Informe de la Conferencia Temática Geografías de la Paz 2017 UGI.

El logo del evento fue elaborado por Alex Carrillo Díaz en base a una foto de Elena D’Algnesse.

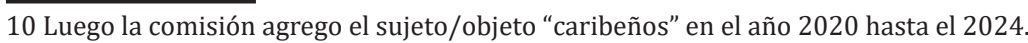


Entre los días, 23, 24 y 25 abril del año 2017, se realizó la" Conferencia Temática Geografías Por la Paz" en la ciudad de La Paz, Bolivia, participando colegas de 35 países, con un total de 110 expositores entre profesores y estudiantes de pre y postgrado. Dicho evento, fue coorganizado con la vicepresidenta de la UGI, Prof. Elena D’Algnesse y la Comisión de Estudios UGI de Geografía Política, además las comisiones de Historia de la Geografía; de Turismo; Globalización, marginación y respuestas regionales y locales; de Estudios Africanos quienes presentaron exposiciones y coordinaron paneles con sus temas de interés y ejes de investigación.

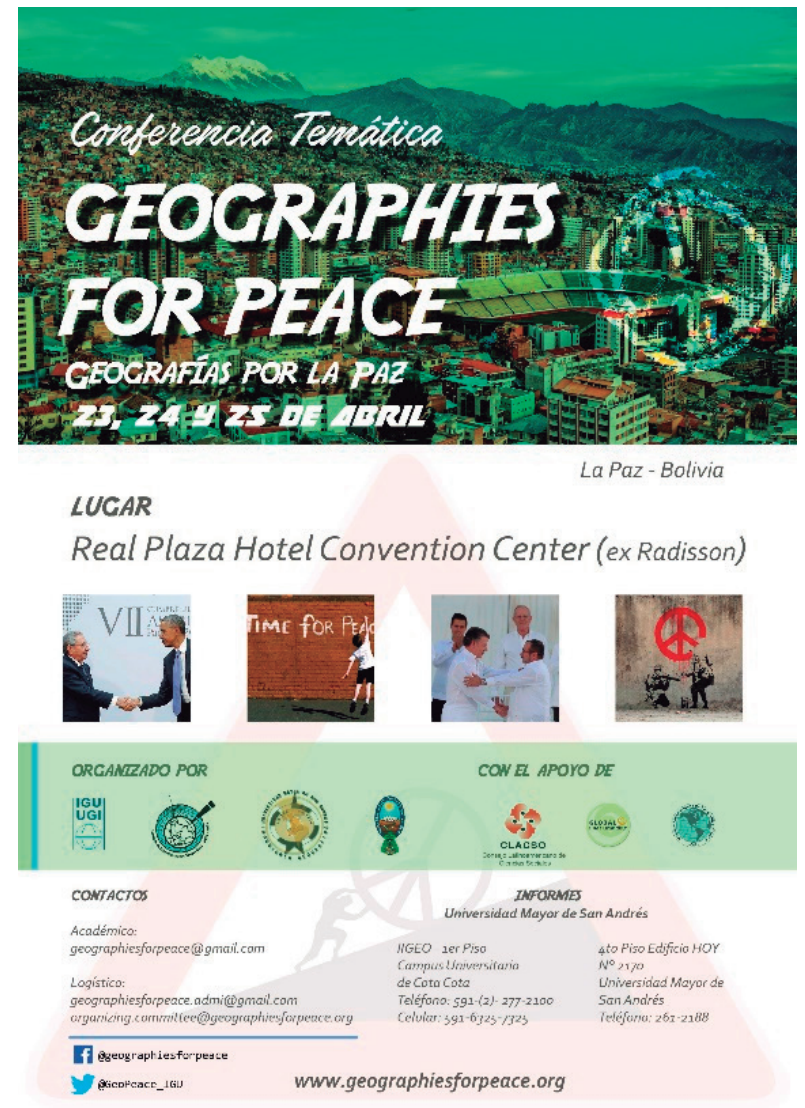

Figura 4. Afiche de la Conferencia Temática 2017

Fuente: Informe de la Conferencia Temática Geografías de la Paz 2017 UGI

Elaboración y diseño: Alex Carrillo Díaz

El evento en mención contó con el apoyo de la Universidad Mayor de San Andrés, de Bolivia, a través del Instituto de Investigaciones Geográficas - IIGEO y de la Vicepresidencia del Estado Plurinacional de Bolivia entre otras instituciones bolivianas. Como bien se sabe la baja participación de los geógrafos latinoamericanos y caribeños en los eventos de la UGI es una urgencia a corregir, también se vio reflejado en la Conferencia Temática, por ello se tomó la decisión que se debiera dar facilidades de viajes e inscripciones a participantes que enviaron sus resúmenes para que obtengan desde becas de viaje, en algunos casos también de inscripción, y por todo lo anterior se logró la activación de los paneles de:

- Geografía, y la construcción de la paz en Colombia/Paz territorial y la negociación de cartografías.

- La paz en Colombia un largo camino

- Pueblos indígenas, territorios de Paz 
Las actividades en mención, estaban en peligro, debido a que no se contaba con la confirmación de casi la mitad de los expositores que enviaron sus resúmenes, sabiendo de la importancia de la firma del acuerdo final de la Paz en Colombia (26 septiembre de 2016) entre el gobierno colombiano y las Fuerzas Armadas Revolucionarias de Colombia - FARC, acto auspiciado por la ONU y siendo el conflicto armado más largo del mundo con casi 70 años de duración. Se consideró imprescindible la participación de académicos e investigadores de esos paneles, debido a ello se apoyó su realización de diversas maneras desde la organización local.

Dentro de las actividades en mención, ocurrió un caso especial de un panel titulado "Un camino hacia la paz entre Chile y Bolivia", el cual, también era un tema coyuntural debido a que no existen relaciones diplomáticas entre ambos países desde el año 1978 por el centenario de la Guerra del Pacifico y en el marco de la queja boliviana por el acceso al mar ante el tribunal de la Haya (Holanda) y que existía un proceso de arbitraje en curso, cuyo fallo fue desfavorable para el país de Bolivia.

El perfil de los asistentes y expositores de la Conferencia Temática UGI “Geografías Por la Paz" - GFP Bolivia 2017; fueron tomadores de decisión, profesionales y/o estudiantes que tienen que ver con el quehacer de las geografías desde el enfoque humano y crítico en sus diferentes disciplinas o formas de estudios afines desde la academia o la praxis.

Durante los días en los que transcurrió la conferencia, se plantearon los siguientes objetivos $^{11}$ :

- Compartir experiencias, proyectos eideas entorno a las geografías por la Paz para crear futuras redes de conocimiento temático con profesores e investigadores de otros continentes con interés futuros proyectos en común.

- Consolidar la comunidad geográfica para trabajar apostando a la transparencia, la colaboración y el conocimiento compartido de información y datos para proyectos de investigación y colaboración.

La conferencia estaba dirigida $\mathrm{a}^{12}$ :

- Tomadores de Decisión, de distintos organismos de gobierno (nacional e internacional) que gestionan proyectos de desarrollo, memoria y postconflicto en sus países o regiones de cualquier parte del mundo.

- Empleados estatales y del sector privado relacionados con las políticas públicas de desarrollo territorial, que dan soporte a la búsqueda de la verdad, paz y reconciliación después de un conflicto armado interno o guerras de diferentes escalas.

- Miembros de grupos de estudios, talleres, de investigación o de grupos de ciudadanos que estén construyendo cartografía social sobre La Paz, mapas colaborativos que impulsen el uso del software libre para generar mapas de Paz en sus comunidades, ciudades o países.

- Académicos (Universidades): profesores y alumnos desde las ciencias sociales, ingenierías, ciencias básicas y humanas con interés en los sesiones propuestas o ejes temáticos a discutir.

- Público general, familias y especialmente niños para incidir en ellos en una política de paz en las y los ciudadanos del mundo.

11 Informe de la Conferencia Temática Geografías de la Paz 2017 UGI 
Se recibieron a evaluar diversas propuestas de sesiones desde las Comisiones de Estudios de la UGI ${ }^{13}$ entre otras de los diferentes colectivos de geógrafos interesados en el tema propuesto, como, por ejemplo:

A. Comisión de Estudios UGI sobre el cambio global y la movilidad humana (globalidad)

A.1 La movilidad humana derivada de la vulnerabilidad y al servicio de la paz

A.2 El papel de la movilidad humana ante la violencia y los conflictos

\section{B. Comisión de Estudios UGI Geografía Política}

B.1 Geografías de la diplomacia y la paz.

B.2 Ciudades de Paz: Nombres de lugares que celebran la paz.

B.3 Intérpretes y traductores como portavoces, constructores de paz o traidores.

B.4 Hermanamientos, ciudades hermanas y diplomacia de ciudadanos: ¿Desviar a los estados por la paz?

B.5 Geografías políticas de Pax Americana y otras formas de paz impuestas por la fuerza

B.6 Geopolítica de la paz y la paz geopolítica

B.7 Prácticas culturales contra la militarización de los territorios ocupados: Una perspectiva comparada.

B.8 Historias comunes y ética de la frontera más allá de la titulación.

B.9 Conflictos transnacionales en África: Migración, movilidad y paz.

B.10 La Unión Africana y la Comunidad Económica Africana: ¿Arreglos territoriales y económicos para la paz en África?

C. Comisión de Estudios UGI de Historia de la Geografía

C.1. Paz en la historia y filosofía de la geografía: ¿qué enfoques posibles?

D. Comisión de Estudios UGI sobre Marginalización, globalización y respuestas regionales y locales

D.1. La globalización como fuente de marginación; La marginalidad como fuente de tensiones y conflictos.

\section{E. Comisión de Estudios UGI Latinoamericanos y Caribeños}

E.1 Pueblos indígenas, territorios de Paz.

E.2 Retos, desafíos y acciones en la búsqueda de la paz en América Latina.

13 Informe anual de la Comision de Estudios Latinoamericanos de la UGI (2016 - 2017). 


\section{F. Comisión de Estudios UGI Geografía del turismo, ocio y cambio global}

F.1 Turismo Internacional y Diplomacia Cultural.

F.2 Movilidad y Geografías de la Paz.

\section{G. Comisión de Estudios UGI Geografía de la educación}

G.1 Educación geográfica para la paz / Geografía enseñanza para la paz.

G.2 Educación geográfica para la comprensión global / Tecnologías geoespaciales en la eeducación geográfica para la paz.

\section{Otras sesiones temáticas}

1. Hacia un nuevo enfoque de la paz y el desarrollo

2. Cooperación territorial y para-diplomacia: un instrumento para la paz

3. Condiciones étnicas, territoriales y políticas de paz en Europa Central y Oriental

4. Perspectivas Anarquistas y Libertarias sobre las Geografías de la Paz

5. Arte y paz

6. Geografía, (post) cooperación al desarrollo y paz

7. Ecología de la paz

8. Redes transfronterizas de mujeres: hacia un nuevo enfoque de la paz y el desarrollo

9. Cartografías violentas

10. Realizar la paz: Desde la perspectiva de la frontera

11. Periferias en el proceso de integración: Conflictos, crisis... y después

12. ¿Secamos su pozo poco profundo? Lo sentimos porque lo necesitamos para nuestras flores destinadas a los mercados de exportación. Hacer un balance de los conflictos emergentes sobre los recursos hídricos (de tierra) en África.

13. Los Oros de la Guerra y Paz: fronteras de los recursos mineros y las historias de la Industria y el imperialismo

14. Geografía Religiosa y Paz (I)

15. Geografía y paz religiosa (II)

16. Paz en los espacios públicos, ¿espacios públicos en paz?

17. Oficina geográfica: la educación para un mundo de paz (Video Sesión)

18. Geografía, y la construcción de la paz en Colombia: "Paz territorial" y la negociación de cartografías 


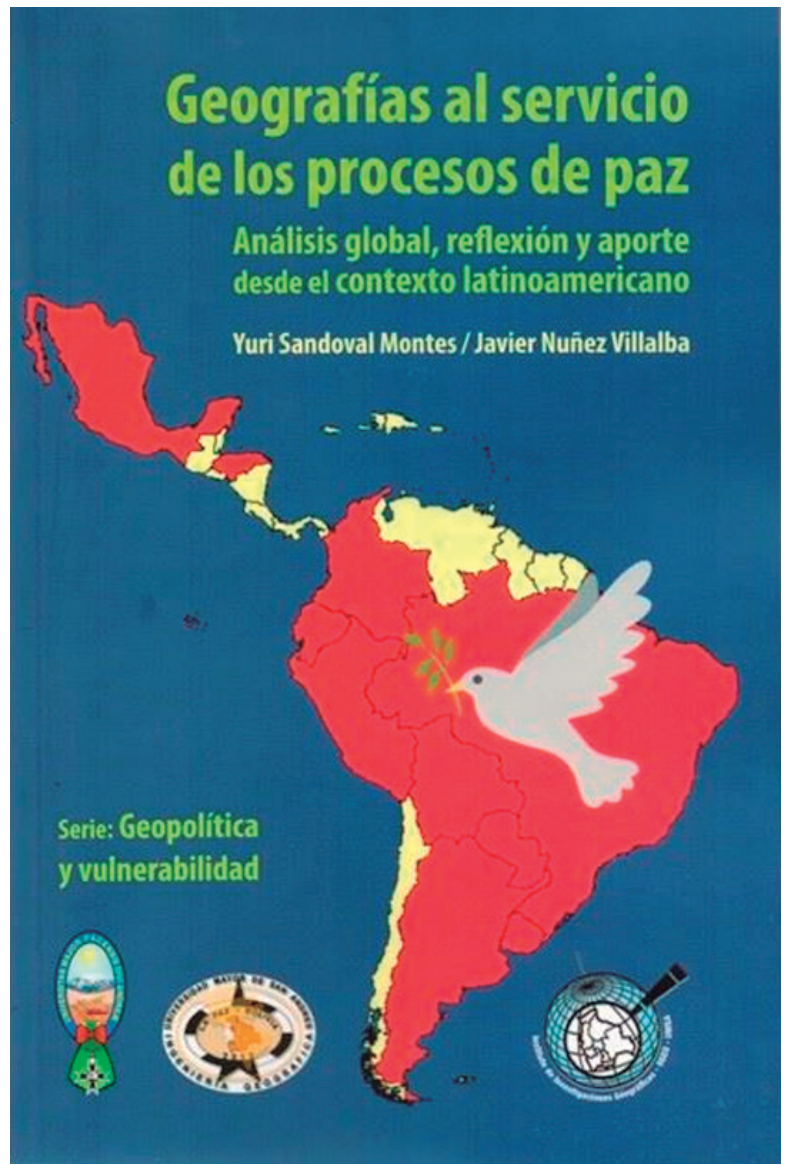

Figura 5. Libro compilatorio de la Conferencia Temática 2017

Fuente: Informe de la Conferencia Temática Geografías de la Paz 2017 UGI

Elaboración y compilación: Yuri Sandoval y Javier Nuñez profesores de la UMSA, Bolivia.

\section{Comentarios complementarios}

En los días posteriores al mes de abril del 2017, se realizó el XVI EGAL en la ciudad de La Paz - Bolivia, donde participaron aprox. 800 geógrafos y geógrafas de América Latina en 12 ejes temáticos, donde con la Comisión Organizadora Local se logró un trabajo en equipo en la organización del mismo. Durante el 2019 en el XVII EGAL Ecuador se continuo con ese trabajo con los organizadores locales, pues la Asociación Geográfica del Ecuador - AGE son quienes representan a la UGI en Ecuador.

Este fue el primer evento co - organizado por las comisiones de la UGI en Latinoamerica y el Caribe luego del 2011 en Chile, es una buena experiencia pues la presencia de la UGI organizando eventos académicos era muy escasa en diversos países de nuestra región.

Desde el 2018 es un deseo confirmado de que se organice un evento académico propio de la Comisión de Estudios Latinoamericanos, explorando las sedes en las ciudades de Lima en Perú, Bogotá en Colombia o Quito en Ecuador, siempre coorganizado con otras comisiones de trabajo para concordar también el tema a presentar, recién este 2021 en una reunión de Comités Nacionales UGI, se tiene conocimiento que se acordó que sea Colombia la sede de la Conferencia Temática, estando por confirmar que sea con el tema de "Geografías de la Paz", un poco para visibilizar el estancado proceso de paz colombiano, que por las elecciones presidenciales del 2022 el tema de la Paz tiene vigencia indudablemente. 
El evento temático UGI del 2017 tuvo como auspiciadores y coorganizadores al Consejo Latinoamericano de Ciencias Sociales - CLACSO a través del GT - Pensamiento Geográfico Critico Latinoamericano y al Instituto Panamericano de Geografia e Historia - IPGH a través de su Sección Nacional de Bolivia el Instituto Geográfico Militar.

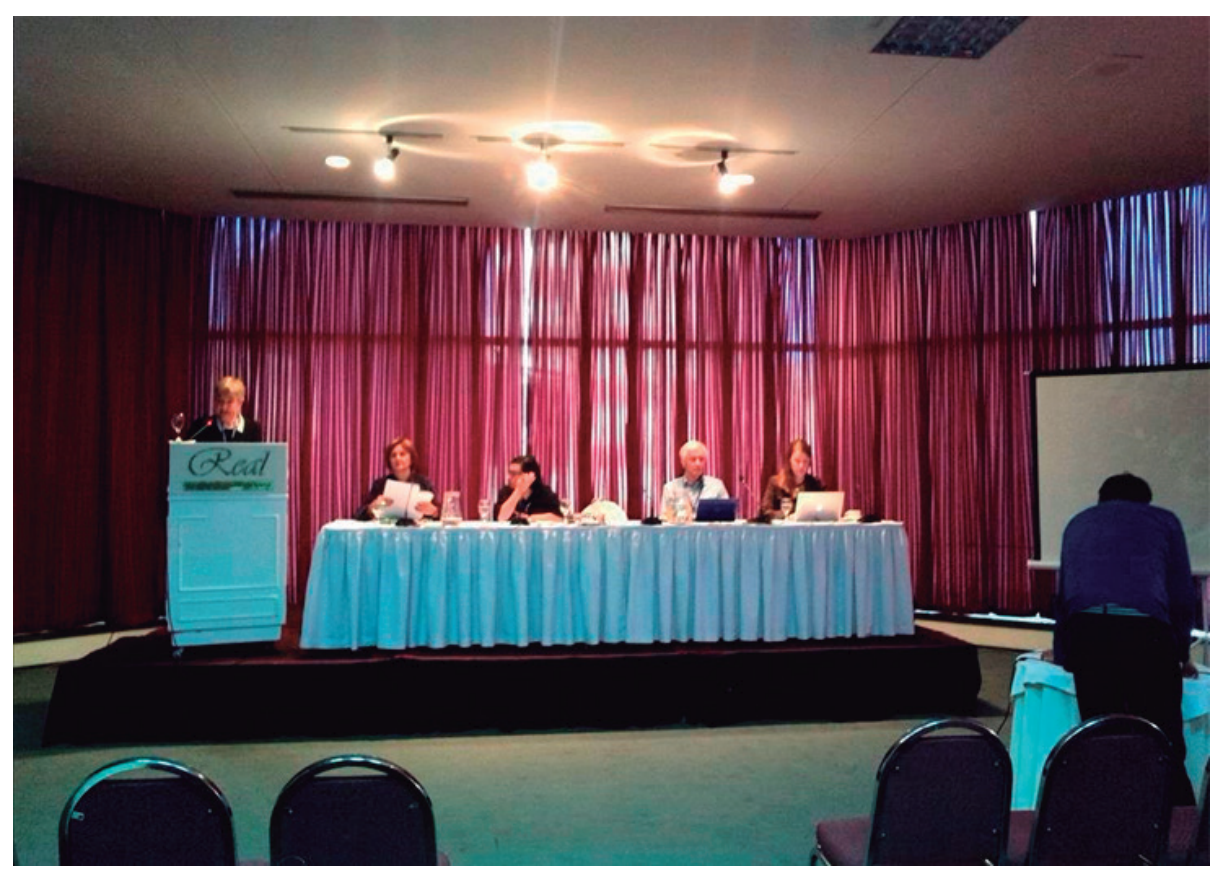

Figura 6. Clausura de la Conferencia Temática La Paz 2017

Fuente: Archivo de Maria Lois y Takashi Yamazaki

\section{Referencias Bibliográficas}

Batalla, A. B. (1957). XVIII CONGRESO INTERNACIONAL DE GEOGRAFIA: Informe de la Delegación Mexicana. Revista Geográfica, 21(47), 60-74. http://www.jstor.org/ stable/40996458 .

Cairo, H. (2019). Geografías de la paz y geografías pacifistas en la Guerra Fría. ACME: An International Journal for Critical Geographies, 18(6), 1167-1183. Retrieved from https:// acme-journal.org/index.php/acme/article/view/1628 .

Cairo, Heriberto \& Jerónimo Ríos. (2019). Los discursos de las élites políticas sobre la paz territorial en Colombia. Revista Española de Ciencia Política 50, 91-113.

Palacio Prieto, José Luis. (2011). Los estudios de Geografía en las universidades de América Latina; desarrollo, situación actual y perspectivas. Investigaciones geográficas, (74), 107124. https://doi.org/10.14350/rig.29757 .

Quiroz, R. y Narvaez, Á. (2014). De la loca geografía de Mistral a la geografía militar de Pinochet: el periodo de la institucionalización geográfica en Chile (1889- 1979). Revista Geográfica de Valparaíso, 49. 30-54. http://www.ucv.cl/uuaa/site/artic/20180316/ asocfile/20180316172735/49_3.pdf

Sandoval Montes, Yuri \& Javier Nuñez Villalba (2017). “Geografías al servicio de los procesos de Paz: análisis global, reflexión y aporte desde el contexto latinoamericano". Instituto de Investigaciones Geográficas-IIGEO; Universidad Mayor de San Andrés-UMSA Plural editores; La Paz - Bolivia.

Union Geográfica Internacional (2017) "Informe Comisión de Estudios Latinoamericanos 2016 - 2017 (C12.27)". Union Geográfica Internacional. http://igu-online.org/wp-content/ uploads/2014/09/C12-27-Latin-American-Studies-2012-2013-Spanish.pdf . 
Urquijo Torres, Pedro Sergio, \& Bocco Verdinelli, Gerardo. (2016). Pensamiento geográfico en América Latina: retrospectiva y balances generales. Investigaciones geográficas, (90), 155-175. https://doi.org/10.14350/rig.47348 .

Vargas, H.M., \& Bomfim, P.R.A. (2014). La Geografía Latinoamericana y la Unión Geográfica Internacional (UGI): los casos de Brasil (1956) y México (1966). Journal of Latin American Geography 13(1), 215-232. https://doi:10.1353/lag.2014.0002 . 